\title{
Altered Discharge Pattern of Basal Ganglia Output Neurons in an Animal Model of Idiopathic Dystonia
}

\author{
Manuela Gernert, Mustapha Bennay, Maren Fedrowitz, Jan H. Rehders, and Angelika Richter \\ Department of Pharmacology, Toxicology and Pharmacy, School of Veterinary Medicine, Hannover, \\ 30559 Hannover, Germany
}

\begin{abstract}
A decreased activity of basal ganglia output neurons is thought to underlie idiopathic dystonias and other hyperkinetic movement disorders. We found recently a reduced spontaneous discharge rate of entopeduncular neurons (internal globus pallidus in primates) in $d t^{s z}$ hamsters, an unique model for idiopathic paroxysmal dystonia in which stress-inducible attacks show an age-dependent severity. Otherwise, it has been suggested that an altered discharge pattern may be more important for the occurrence of dystonia than a reduced discharge rate. Based on qualitative and computerized quantitative evaluations of interspike interval histograms and spike trains of extracellularly recorded single neurons, we investigated the spontaneous discharge pattern of GABAergic entopeduncular and nigral neurons in $d t^{s z}$ hamsters at different ages. The discharge pattern of entopeduncular neurons was highly irregular and showed an altered burst-like firing in $d t^{s z}$ hamsters at the age of the most marked expression of dystonia when
\end{abstract}

The basal ganglia have been implicated in the development of several movement disorders for decades. However, the exact role played by these structures for the occurrence of idiopathic dystonias has been remained elusive. Dystonia is a common neurological syndrome characterized by involuntary, sustained contractions of opposing muscles, causing abnormal movements or postures (Fahn et al., 1998). Approximately two-thirds of cases are idiopathic (Kramer et al., 1995).

The current functional model of the basal ganglia suggests that dystonias and other dyskinesias, including levodopa-induced dyskinesia in patients with Parkinson's disease, result from abnormally low activity of basal ganglia output structures (Wichmann and DeLong, 1996; Berardelli et al., 1998; Vitek and Giroux, 2000). Hypoactivity of the GABAergic neurons of the internal part of the globus pallidus (GPi) and/or the substantia nigra pars reticulata $(\mathrm{SNr})$ would disinhibit the motor thalamus and cortex and thereby giving rise to the abnormal movements (CeballosBaumann et al., 1995; Playford et al., 1998; Guehl et al., 2000). An

\footnotetext{
Received March 4, 2002; revised May 7, 2002; accepted May 17, 2002.

This work was supported by Deutsche Forschungsgemeinschaft Grants Ge 1103/ 1-1 and $\mathrm{Ri} 845 / 1-1$. We are grateful to Claudia Brandt for assisting in the classification of firing patterns. We thank Christiane Bartling, Michael Weißing, and Mirja Becker for their technical assistance.

Correspondence should be addressed to Dr. M. Gernert, Department of Pharmacology, Toxicology and Pharmacy, School of Veterinary Medicine Hannover, Bünteweg 17, D-30559 Hannover, Germany. E-mail: manuela.gernert@tiho-hannover.de.

M. Bennay's present address: Department of Neuropharmacology, Brain Research Institute, University of Bremen, 28334 Bremen, Germany.

J. H. Rehders present address: CP-Pharma GmbH, 31303 Burgdorf, Germany.

A. Richter's present address: Institute of Pharmacology and Toxicology, School of Veterinary Medicine, Freie Universität Berlin, 14195 Berlin, Germany.

Copyright (C) 2002 Society for Neuroscience $\quad 0270-6474 / 02 / 227244-10 \$ 15.00 / 0$
}

compared with age-matched nondystonic controls. In line with a recently reported normalization of discharge rates after agedependent disappearance of dystonia, we found an almost complete normalization of the discharge pattern of entopeduncular neurons after remission of dystonia in $d t^{s z}$ hamsters. Investigations of GABAergic nigral neurons, reported recently to have the same spontaneous discharge rates in dystonic and nondystonic hamsters, did not show an altered firing pattern in $d t^{s z}$ hamsters. The present data clearly indicate the fundamental importance of an altered discharge pattern of entopeduncular neurons for the expression of paroxysmal dystonia, and probably also for other dyskinesias, and may explain the improvements obtained by pallidotomy in dystonic patients despite an obviously reduced pallidal output.

Key words: basal ganglia; dt ${ }^{\text {sz }}$ hamster; movement disorders; entopeduncular nucleus; globus pallidus; substantia nigra pars reticulata; single-unit recordings; firing pattern

average decrease in discharge rates of GPi neurons was reported recently for dystonia patients (Vitek et al., 1999).

The $d t^{s z}$ mutant hamster shows clinical and pharmacological characteristics, which resemble idiopathic paroxysmal dystonia (primary paroxysmal nonkinesiogenic dystonia) in humans (Löscher et al., 1989; Demirkiran and Jankovic, 1995; Richter and Löscher, 1998). In this subtype of dystonia, attacks of generalized dyskinesia last up to several hours and can be provoked by stress. The dystonic syndrome in $d t^{s z}$ hamsters shows an age-dependent time course with maximum severity at an age of 30-40 d and a remission of stress-inducible attacks at an age of $\sim 10$ weeks (Richter and Löscher, 1993, 1998). The age dependence allows investigations of the importance of physiological alterations in the pathogenesis of dystonia by ontogenetic studies. We provided recently evidence for a dramatically reduced mean discharge rate of neurons in the entopeduncular nucleus (EPN) (the rodent's homolog of the GPi in primates) of $d t^{s z}$ hamsters at the most sensitive age of dystonia (Gernert et al., 2000). A normalization of the EPN discharge rate was found recently after spontaneous remission of stress-inducible attacks (Bennay et al., 2001). These findings clearly support the current hypothesis of a reduced basal ganglia output as the underlying mechanism of dystonia.

However, this model of basal ganglia dysfunctions seems to be incomplete (Filion, 2000), because pallidotomy, which causes an additional reduction of basal ganglia output, has been reported to improve dystonia in patients (Lozano et al., 1997; Bhatia et al., 1998; Ondo et al., 1998; Vitek et al., 1998). An attempt to explain this paradox is that an abnormal pattern of discharge, as suggested for GPi neurons of patients with idiopathic generalized 
dystonia, could be more important than the decrease of the average discharge rate (Wichmann and DeLong, 1996; Vitek et al., 1999; Vitek and Giroux, 2000).

In contrast to the fundamental importance of the GPi or EPN output activity for the expression of dystonia, the role played by the $\mathrm{SNr}$ is less obvious. Single-unit recordings from the $\mathrm{SNr}$ in $d t^{s z}$ hamsters did not reveal alterations in spontaneous discharge rates, despite indications for an altered responsiveness of the $\mathrm{SNr}$ neurons to drugs that disturb GABAergic function (Gernert et al., 1999c; Fedrowitz et al., 2002).

In the present study, we have undertaken a comprehensive ontogenetic study of the spontaneous discharge patterns of basal ganglia output neurons in the dystonic hamster. With regard to the findings mentioned above, the discharge patterns were investigated (1) from EPN neurons of $d t^{s z}$ hamsters at the most sensitive age of dystonia when the spontaneous discharge rate is reduced, (2) from EPN neurons of $d t^{s z}$ hamsters after spontaneous remission of stress-inducible attacks when the spontaneous discharge rate is normalized, and (3) from $\mathrm{SNr}$ neurons of $d t^{s z}$ hamsters at the most sensitive age of dystonia.

\section{MATERIALS AND METHODS}

Animals. The experiments were performed using two groups of Syrian hamsters. Mutant dystonic hamsters are of an inbred line in which dystonia is transmitted by an autosomal recessive gene (genetic symbol $d t^{s z}$ ), and age-matched nondystonic control hamsters are of an outbred line. The $d t^{s z}$ hamsters were obtained by selective breeding as described in detail previously (Löscher et al., 1989). The control hamsters were obtained by breeding pairs, which were provided by a commercial breeder (Central Institute for Laboratory Animal Breeding, Hannover, Germany). In both animal groups, males and females were used. All dystonic and control hamsters were born and kept under the same controlled environmental conditions (ambient temperature $23^{\circ} \mathrm{C} ; 14 / 10$ hr light/dark cycle; lights on at 5:00 A.M.). Standard Altromin diet and tap water were allowed ad libitum. All experiments were done in compliance with the German Animal Welfare Act.

Induction of dystonic attacks and severity score of dystonia. In mutant hamsters, dystonic attacks can be induced reproducibly by a triple stimulation technique (Löscher et al., 1989; Richter and Löscher, 1998). These stressful stimuli consist of (1) taking the animal from its home cage and placing it on a balance, (2) injection of saline, and (3) placement of the animal in a new plastic cage for a $3 \mathrm{hr}$ observation period. During this time, $d t^{s z}$ hamsters develop a sequence of abnormal movements and postures. Therefore, the severity of dystonia can be rated by a six-point score system (for details, refer to Löscher et al., 1989). All animals were examined for the presence of dystonia after weaning at the age of $21 \mathrm{~d}$ and at the age of $\sim 30 \mathrm{~d}$ by the triple-stimulation technique. Only $d t^{s z}$ hamsters that showed severe dystonia after weaning were used for the present experiments. Animals used for electrophysiological experiments after spontaneous remission of stress-inducible dystonic attacks were again tested at an age of 90 and $100 \mathrm{~d}$ by the triple-stimulation procedure. Only $d t^{s z}$ hamsters that showed the typical age-dependent time course (severe dystonia at an age of 21 and $30 \mathrm{~d}$ and a remission on days 90 and 100) were used for single-unit recordings.

Single-unit recordings in anesthetized animals. The discharge pattern of EPN and SNr neurons was evaluated from in vivo extracellular single-unit recordings. The experiments were done in $d t^{s z}$ hamsters at the most sensitive age of dystonia at an age of 32-43 d and age-matched nondystonic controls (Gernert et al., 2000; Fedrowitz et al., 2002). Additional recordings from the EPN were done in $d t^{s z}$ hamsters after spontaneous remission of stress-inducible attacks at an age of 123-152 d and agematched nondystonic controls (Bennay et al., 2001). Extracellular singleunit recordings were performed using standard in vivo techniques, as described in detail recently (Gernert et al., 1999b,c, 2000). Briefly, the animals were anesthetized with methohexital $(55 \mathrm{mg} / \mathrm{kg}$, i.p.) and fentanyl $(0.05 \mathrm{mg} / \mathrm{kg}$, i.p.) during surgical preparation. During recording, the animals were anesthetized with fentanyl $\left(0.05 \mathrm{mg} \cdot \mathrm{kg}^{-1} \cdot \mathrm{hr}^{-1}\right.$, i.v. $)$ and paralyzed with gallamine $\left(15 \mathrm{mg} \cdot \mathrm{kg}^{-1} \cdot \mathrm{hr}^{-1}\right.$, i.v. $)$. The anesthesia used here has been shown previously in rodents at least not to alter the spontaneous firing rate of $\mathrm{SNr}$ neurons when compared with conscious animals (Löscher et al., 1995). The hamsters were vagotomized and artificially ventilated with $\mathrm{O}_{2}$-room air. During the experiments, the heart rate and body temperature, maintained at $37^{\circ} \mathrm{C}$ by heat pad, were continuously monitored. Recordings on $\mathrm{EPN}$ or $\mathrm{SNr}$ neurons were started not earlier than $1 \mathrm{hr}$ after the last injection of the short-acting barbiturate methohexital.

Single-barrel extracellular recording microelectrodes were pulled (PE-2 vertical puller; Narishige, Tokyo, Japan) from a filamented glass electrode (Hilgenberg, Malsfeld, Germany) and the tip broken back to an external diameter of $\sim 5-10 \mu \mathrm{m}$. The electrodes were backfilled with horseradish peroxidase (3\%) in Tris-buffered saline for marking the tip location. This procedure yielded electrodes with impedances of 2-6 $\mathrm{M} \Omega$ when tested ex vivo at $1200 \mathrm{~Hz}$.

The microelectrode was lowered to the EPN or SNr to just above the target region through a small burr hole in the skull. The stereotaxic coordinates relative to bregma according to the method of Paxinos and Watson (1998) were as follows (in mm): (1) EPN, posterior (P), 0.3; lateral (L), 2.2; ventral (V), 6.0; (2) SNr, P, 3.2; L, 2.0; V, 5.0. The

Table 1. Correlation of spontaneous discharge rates and ISI parameters

\begin{tabular}{|c|c|c|c|c|c|c|c|c|}
\hline \multirow{2}{*}{$\begin{array}{l}\text { Brain region } \\
\text { (age in } d)\end{array}$} & \multirow{2}{*}{$\begin{array}{l}\text { Animal } \\
\text { group }\end{array}$} & \multirow{2}{*}{$\begin{array}{l}\text { Neurons } \\
\text { (animals) }\end{array}$} & \multirow{2}{*}{$\begin{array}{l}\text { Discharge rate } \\
\text { (spikes/sec) }\end{array}$} & \multicolumn{5}{|c|}{ Spearman correlation of discharge rates and ISI parameters } \\
\hline & & & & & Mean & Mode & Asym. & Kurtosis \\
\hline \multirow[t]{4}{*}{ EPN (32-42) } & \multirow[t]{2}{*}{$\mathrm{c}$} & \multirow[t]{2}{*}{$36(16)$} & \multirow[t]{2}{*}{$24.8 \pm 2.5$} & $r$ & $-0.965^{*}$ & $-0.378^{*}$ & 0.315 & $0.784^{*}$ \\
\hline & & & & $p$ & $<0.0001$ & 0.023 & 0.062 & $<0.0001$ \\
\hline & \multirow[t]{2}{*}{$d t^{s z}$} & \multirow[t]{2}{*}{$30(15)$} & $8.4 \pm 1.4$ & $r$ & $-0.647^{*}$ & -0.128 & 0.113 & $0.683^{*}$ \\
\hline & & & $(-66.1 \%)^{a}$ & $p$ & $<0.0001$ & 0.494 & 0.550 & $<0.0001$ \\
\hline \multirow[t]{4}{*}{ EPN (123-152) } & \multirow[t]{2}{*}{$\mathrm{c}$} & \multirow[t]{2}{*}{$26(10)$} & \multirow[t]{2}{*}{$30.8 \pm 1.1$} & $r$ & $-0.860^{*}$ & -0.082 & 0.232 & 0.119 \\
\hline & & & & $p$ & $<0.0001$ & 0.686 & 0.252 & 0.560 \\
\hline & \multirow[t]{2}{*}{$d t^{s z}$} & \multirow[t]{2}{*}{$25(11)$} & $28.2 \pm 1.1$ & $r$ & $-0.940^{*}$ & $-0.439^{*}$ & -0.053 & -0.135 \\
\hline & & & $(-8.4 \%)^{b}$ & $p$ & $<0.0001$ & 0.028 & 0.798 & 0.517 \\
\hline \multirow[t]{4}{*}{$\mathrm{SNr}(32-43)$} & \multirow[t]{2}{*}{$\mathrm{c}$} & \multirow[t]{2}{*}{$21(15)$} & \multirow[t]{2}{*}{$22.6 \pm 1.9$} & $r$ & $-0.969^{*}$ & 0.024 & 0.335 & $0.610^{*}$ \\
\hline & & & & $p$ & $<0.0001$ & 0.919 & 0.138 & 0.003 \\
\hline & \multirow[t]{2}{*}{$d t^{s z}$} & \multirow[t]{2}{*}{$40(31)$} & $22.8 \pm 1.6$ & $r$ & $-0.958^{*}$ & $-0.348^{*}$ & 0.009 & $0.333^{*}$ \\
\hline & & & $(+0.9 \%)^{b}$ & $p$ & $<0.0001$ & 0.028 & 0.957 & 0.036 \\
\hline
\end{tabular}

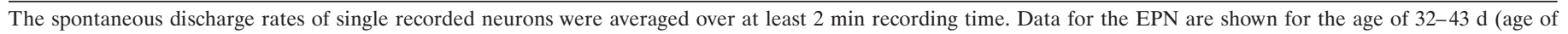

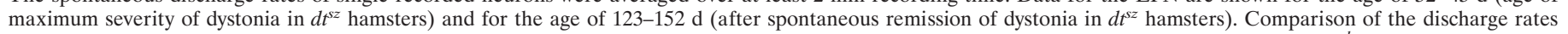

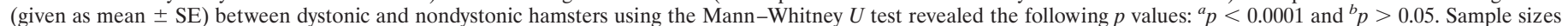

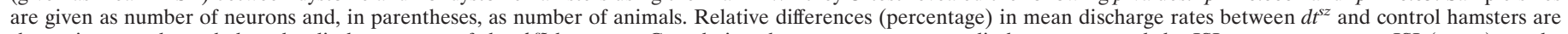

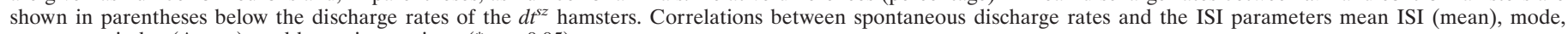
asymmetry index (Asym.), and kurtosis are given $(* p<0.05)$. 
electrode was then slowly lowered under continuous recording of extracellular neural signals until a spontaneously active EPN or $\mathrm{SNr}$ neuron was identified. After identifying a stable neuron, the spontaneous firing rate was recorded for at least $2 \mathrm{~min}$. Because dystonia in $d t^{s z}$ hamsters is not lateralized, the experiments could be performed on either brain hemisphere. When possible, several neurons per animal were recorded.

Standard techniques for amplifying, filtering, and processing of extracellular neuronal activity were used by means of the DataWave System (WissTech, Spechbach, Germany). Single units were discriminated online by amplitude threshold and offline by spike template matching using the cluster analysis module of the DataWave System. Units of dystonic and nondystonic animals were recorded and separated in a mixed manner under identical experimental conditions.

At the end of each recording period per brain side, the location of the electrode tip was marked by iontophoretical ejection of a small amount of horseradish peroxidase (Simons and Land, 1987). For this purpose, a pulsed anodal current ( $7 \mathrm{sec}$ on, $7 \mathrm{sec}$ off) of $2.2 \mu \mathrm{A}$ was applied for $2 \mathrm{~min}$. Finally, the hamsters were deeply anesthetized with pentobarbital and transcardially perfused. The brains were processed for histological verification of the recording sites as described in detail previously (Gernert et al., 1999b). Only neurons located in the EPN or SNr were used for further evaluation of data.

Drugs. Methohexital (Brevimytal-Natrium $500 \mathrm{mg}$; Lilly, Giessen, Germany) was dissolved in sterile saline to obtain a concentration of 11 $\mathrm{mg} / \mathrm{ml}$ and stored at $4^{\circ} \mathrm{C}$. Fentanyl (Fentanyl-Janssen; Janssen, Neuss, Germany) was used as commercial solution. Gallamine (Gallamine triethiodide) and pentobarbital (Pentobarbital-Natrium) were purchased from Sigma (Deisenhofen, Germany) and dissolved in sterile saline.

Evaluation of spontaneous discharge rate, firing pattern, and statistics. The spontaneous discharge rates of EPN and SNr neurons were averaged over the recording time and then were averaged per animal group. Thus, different from previous descriptions (Gernert et al., 2000; Bennay et al., 2001), the mean discharge rates given in the present study were calculated without previous averaging per animal.

Differences in the spontaneous discharge pattern of EPN and $\mathrm{SNr}$ neurons between dystonic and nondystonic animals were determined by comparing the interspike interval histograms (ISIH) together with visual inspections of the spike trains similar to the methods described previously by our group (Gernert et al., 1999b) and other groups (Hassani et al., 1996; Ni et al., 2000; Rohrbacher et al., 2000). The ISIHs were calculated for a time period of 1-2 min. The resolution was $1 \mathrm{msec}$, and intervals up to $500 \mathrm{msec}$ were considered. The ISIHs were produced with an event interval histogram module (DataWave). The ISIHs were used also for verification of the reliability of the used spike separation method. Refractory periods of typically $1-3 \mathrm{msec}$ were observed in most of the recorded units of all animal groups and from both brain locations, when the short interval bins of the ISIHs were examined.

According to the ISIHs together with the spike trains, firing patterns were classified into the following types. (1) Burst-like firing pattern consisting of intermittent grouped firing separated by periods of pauses or low-frequency tonic activity. The ISIHs of these neurons were characterized by a positively skewed distribution, i.e., by a large fraction of short interspike intervals (ISI), in the following termed "burst-like skewed". (2) Burst-like firing pattern as before, but the ISIHs were characterized by a multimodal, i.e., typically double-peaked (bimodal), distribution of the ISIs, indicating transition to rhythmic burst-like firing (in the following, termed "burst-like multimodal"). In some EPN neurons a trimodal ISI distribution was observed, which might result from irregularities in the spike frequency during the recording of these neurons. (3) Burst discharge pattern consisted of trains of three or more spikes occurring within a relatively short interval separated by clear pauses. The ISIH showed an initial sharp peak with a narrow range of a large fraction of the ISIs. (4) Irregular firing pattern was characterized by a flat, i.e., a random, distribution of the ISIs, which sometimes showed mild positive skewness. (5) Regular tonic firing pattern was characterized by ISIHs showing a symmetric distribution of ISIs. The classifications were performed independently by different investigators in a blinded manner with respect to either the hypotheses behind the study or which group of animals and which location the data were derived from.

Several ISIH parameters were quantitatively evaluated (Hassani et al., 1996; Gernert et al., 1999b). The "mode" resembles the most frequent ISI. Variations to the Gaussian distribution were evaluated by the "asymmetry index." The asymmetry index is the ratio of the mode to the mean ISI. This ratio gives information on the shape of the ISIH and will be unity if there is a Gaussian distribution of the ISIs. A ratio $<1$ reflects an asymmetrical shape, indicating a large fraction of short ISIs (positively skewed). This is expected when there is burst-like activity. Differences to a Gaussian distribution of ISIs were also determined by evaluation of the "kurtosis." The kurtosis (fourth moment normalized by dividing by squared variance) of a distribution reflects its degree of peakedness relative to the length and size of its tails. A kurtosis of zero reflects a normal distribution, positive values a sharp peak (leptokurtic), and negative values a flat shape (platykurtic). The kurtosis provides information on the regularity of spiking.

The statistical significance of differences in the fractions of defined cell types, determined by a specific discharge pattern, between dystonic and nondystonic hamsters, and for age-dependent changes, were calculated using the Fisher's exact test. The statistical significance of differences in ISIH parameters between dystonic and nondystonic animals and for age-dependent changes were calculated using the Mann-Whitney $U$ test. For evaluation of correlations between neuronal discharge rates and ISIH parameters, the Spearman rank-order correlation test was used. All tests were used two-tailed, and, in all cases, an error probability of $<5 \%$ was considered significant.

\section{RESULTS}

\section{Spontaneous discharge rates and time course of EPN and SNr neurons}

Shape and time course of extracellularly recorded spikes of EPN and SNr neurons did not differ between dystonic and nondystonic hamsters (data not shown). The spikes exhibited the electrophysiological characteristics of GABAergic neurons of basal ganglia output structures (Gernert et al., 1999c), i.e., all recorded spikes
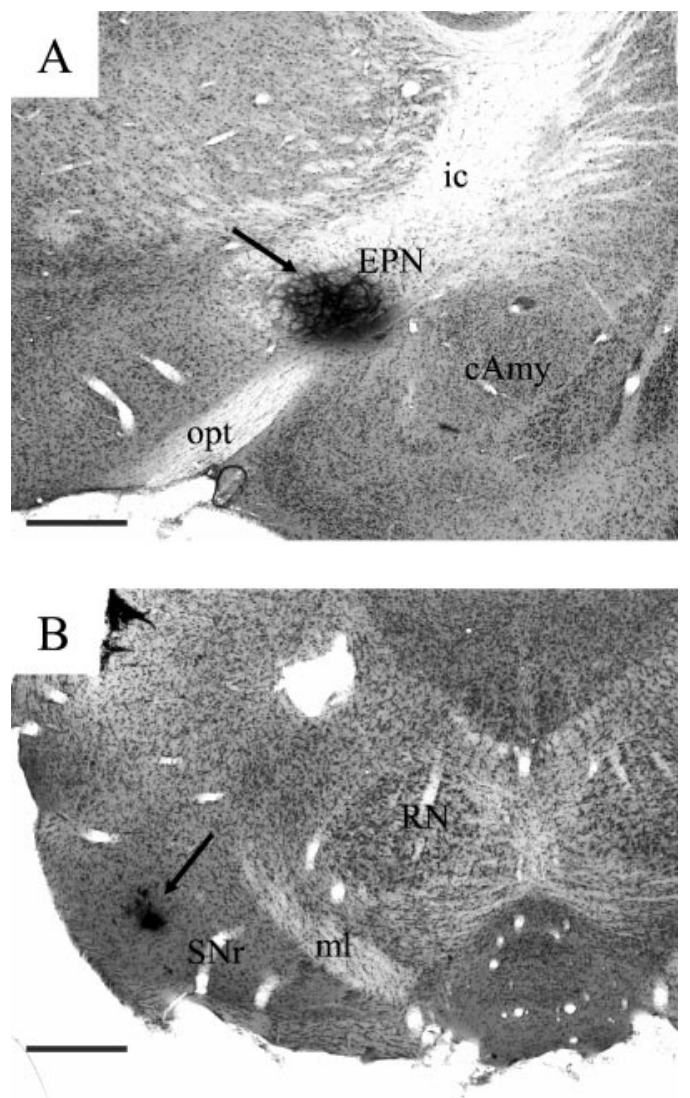

Figure 1. Histological photomicrographs of coronal sections showing recording sites within the EPN $(A)$ of a $d t^{s z}$ hamster and the $\mathrm{SNr}(B)$ of a control hamster. The location of the electrode tip was marked by iontophoretical injection of horseradish peroxidase (arrow). The sections were stained with diaminobenzidine/ $\mathrm{Ni}^{2+}$ and counterstained with neutral red. For additional details, see Materials and Methods. cAmy, Central amygdaloid nucleus; $i c$, internal capsule; $m l$, medial lemniscus; opt, optic tract; $R N$, red nucleus. Scale bar, $0.5 \mathrm{~mm}$. 
1

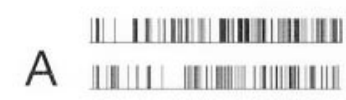

2
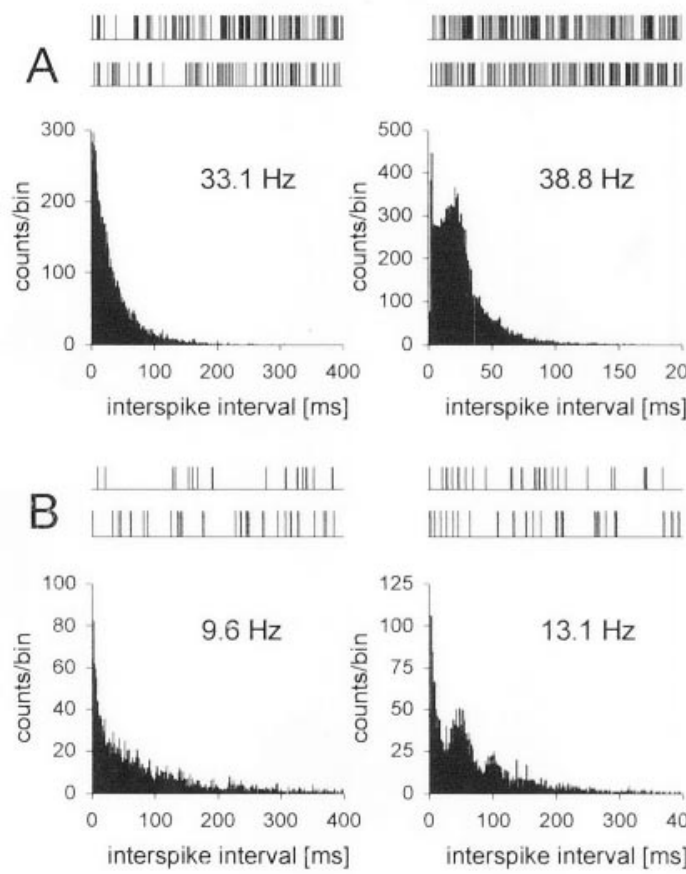

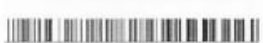

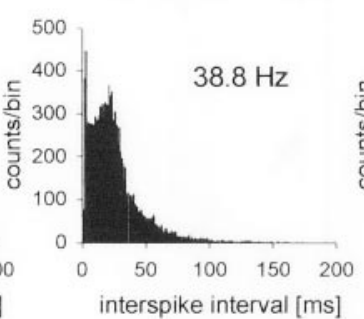

$\lfloor\amalg \amalg|\amalg \amalg \amalg+| \| 1 \mid$ \|\|$\|||||||\| \|||||$

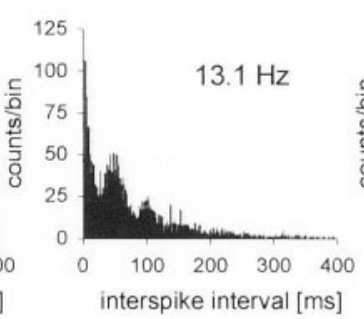

3
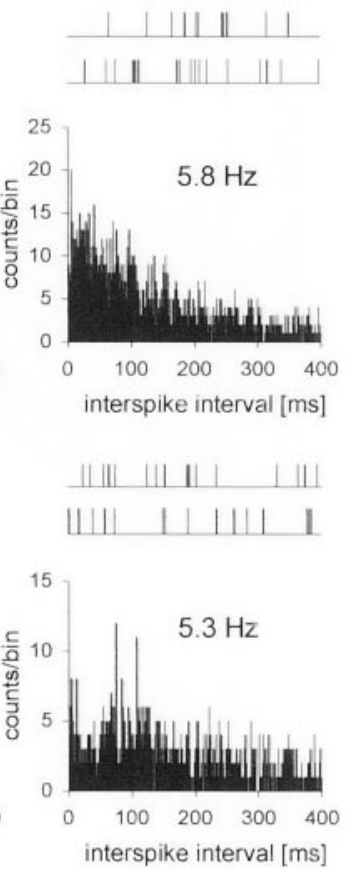
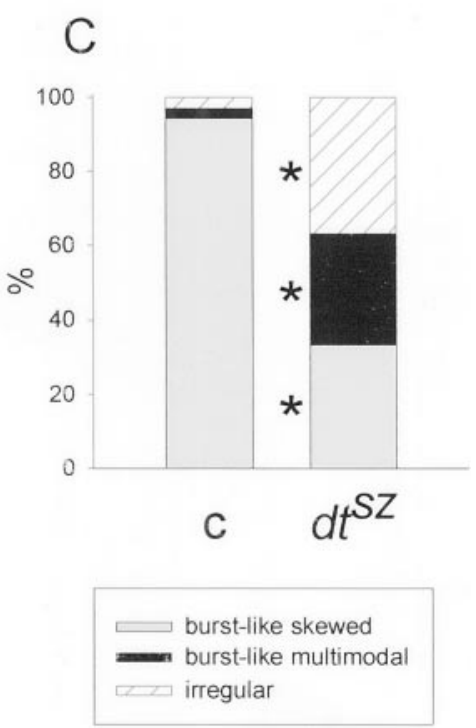

Figure 2. Discharge pattern of in vivo extracellularly recorded EPN neurons of nondystonic $(A)$ and dystonic $(B)$ hamsters at the most sensitive age of dystonia. Trains of discriminated spikes drawn as raster plots (each line is $2.5 \mathrm{sec}$ ) and, below, ISIHs illustrate the three different types of spontaneous EPN discharge patterns (1-3) observed. The neurons 1 in $A$ and $B$ were defined as burst-like with positively skewed distribution of the ISIs. The neurons 2 in $A$ and $B$ were classified as burst-like with a multimodal, i.e., at least showing a double-peaked (bimodal), distribution of the ISIs. The neurons 3 in $A$ and $B$ were characterized by a flat, i.e., random, ISI distribution resembling irregular firing. Each bin of the ISIHs has a duration of 1 msec. The ISIs are plotted up to intervals of $400 \mathrm{msec}$. Note that the ISIH of neuron 2 in $A$ is presented up to only 200 msec for better representation of the bimodal distribution. The discharge rates of the illustrated neurons are given in Hertz within the ISIHs. The relative fraction of defined EPN neurons from nondystonic $(c)$ and dystonic $\left(d t^{s z}\right)$ hamsters is shown in $C$. In dystonic hamsters, the percentage of EPN neurons showing irregular firing and EPN neurons defined as burst-like multimodal increased significantly in favor of a significant decrease in neurons with a burst-like positively skewed pattern $\left({ }^{*} p<0.01\right)$. Total numbers of neurons are as follows: $n=36$ cells from control hamsters; $n=30$ cells from $d t^{s z}$ hamsters. For additional explanations and for exact $p$ values, see Results.

showed a biphasic (positive/negative) time course with an overall duration of $\sim 0.6-1.5 \mathrm{msec}$.

The spontaneous discharge rates of EPN and SNr neurons of dystonic and nondystonic hamsters have been described recently in detail by our group (Gernert et al., 2000; Bennay et al., 2001; Fedrowitz et al., 2002). The present calculations of mean firing rates of basal ganglia output neurons confirm the previous findings. The mean discharge rate of EPN neurons at the most sensitive age of dystonia was found to be significantly reduced by $66.1 \%$ in dystonic hamsters compared with controls $(p<0.0001)$ (Table 1). The mean EPN discharge rate was found to be normalized in older animals after spontaneous remission of stressinducible attacks $(p>0.05)$ (Table 1$)$. In contrast, there was no significant difference in mean $\mathrm{SNr}$ discharge rates between dystonic and nondystonic hamsters $(p>0.05)$ (Table 1).

\section{Discharge pattern of EPN neurons at the most sensitive age of dystonia}

A total of 66 neurons recorded from the EPN of 31 hamsters could be used for analysis of spontaneous discharge patterns at the most sensitive age of dystonia, of which 30 neurons were from $15 d t^{s z}$ hamsters and 36 neurons were from 16 nondystonic control hamsters. An example of electrode location is shown in Figure $1 A$.

EPN neurons of both dystonic and nondystonic hamsters at the most sensitive age of dystonia showed three different spontaneous discharge patterns based on the ISIHs and the spike trains. These patterns ranged from burst-like skewed (Fig. 2A,B, neurons 1), burst-like multimodal (Fig. 2A,B, neurons 2), and irregular firing (Fig. 2A,B, neurons 3). The majority of EPN neurons from nondystonic control hamsters was defined as burst-like skewed (94.4\%) (Fig. 2C). One neuron showed a burst-like bimodal discharge pattern, and one neuron fired irregularly ( $2.8 \%$ each) (Fig. 2C).

Clearly different from the control animals, EPN neurons of $d t^{s z}$ hamsters showed a shift toward irregular and burst-like multimodal firing pattern, the latter one of which six neurons were defined by a bimodal and three neurons by a trimodal ISI distribution (Fig. 2B, neuron 2). The relative fraction of neurons showing irregular firing (36.7\%) and burst-like multimodal firing (30.0\%) increased significantly ( $p=0.0007$ and $p=0.0038$, respectively) in favor of a significant decrease $(p<0.0001)$ in neurons with a burst-like skewed pattern (33.3\%) (Fig. 2C).

Quantitative evaluation of the ISIH parameters confirmed the observation that the EPN neurons of $d t^{s z}$ hamsters at the most sensitive age of dystonia showed a more irregular discharge pattern compared with controls. The kurtosis was significantly lower in $d t^{s z}$ hamsters compared with controls $(3.18 \pm 1.06$ in mutants vs $10.07 \pm 1.52$ in controls; $p<0.0001$ ) (Fig. $3 D$ ), i.e., the ISIs showed a flat distribution in mutants rather than the peaked ISI distribution found in controls. The mean ISI of EPN neurons 

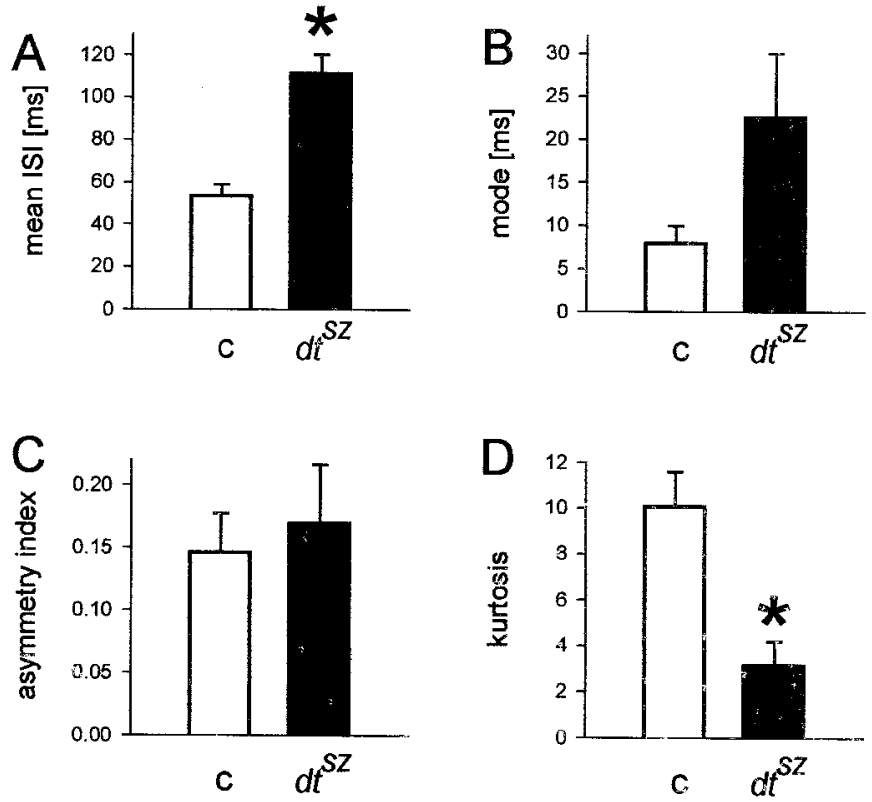

Figure 3. Quantitative evaluation of ISIH parameters of EPN neurons recorded extracellularly from nondystonic control hamsters $(c ; n=36$ neurons) and dystonic hamsters ( $d t^{s z} ; n=30$ neurons) at the most sensitive age of dystonia. Error bars represent mean + SE. The mean ISI $(A)$ was significantly shifted to higher values in dystonic hamsters compared with controls $\left({ }^{*} p<0.01\right)$. The mode $(B)$ and the asymmetry index $(C)$ did not show significant intergroup differences. The kurtosis $(D)$ was significantly lower in $d t^{s z}$ hamsters compared with controls, confirming a more irregular firing of the EPN neurons in mutants $\left({ }^{*} p<0.01\right)$. For additional explanations and for exact $p$ values, see Results.

significantly shifted to higher values in dystonic compared with nondystonic hamsters $(111.58 \pm 9.04$ vs $53.48 \pm 5.52 \mathrm{msec} ; p<$ 0.0001 ) (Fig. $3 A$ ), and the mode tended to be higher in mutants versus controls $(22.57 \pm 7.50$ vs $8.00 \pm 1.95 \mathrm{msec} ; p=0.294)$ (Fig. $3 B)$, but the latter difference failed to be significant. The asymmetry index did not differ significantly between dystonic and nondystonic hamsters $(0.17 \pm 0.05$ vs $0.15 \pm 0.03 ; p=0.056)$ (Fig. $3 C$ ), as could be expected, because this parameter does not differentiate between unimodal and multimodal, positively skewed, ISI distributions. The changes in discharge patterns described here were significantly correlated with the drastically reduced discharge rate of EPN neurons found in $d t^{s z}$ hamsters at the most sensitive age of dystonia (Table 1).

\section{Discharge pattern of EPN neurons after spontaneous remission of stress-inducible attacks}

A total of 51 neurons recorded from the EPN of 21 hamsters could be used for analysis of spontaneous discharge patterns after spontaneous remission of stress-inducible attacks, of which 25 neurons were from $11 d t^{s z}$ hamsters and 26 neurons were from 10 nondystonic control hamsters.

The cell types defined were as follows: burst-like skewed (Fig. 4A, B, neurons 1) and burst-like multimodal (Fig. 4A, $B$, neurons $2, B$, neuron 3 ) in nondystonic and dystonic hamsters and transition to more regular firing in nondystonic hamsters (Fig. 4A, neuron 3). The majority of EPN neurons in older nondystonic hamsters were defined as burst-like skewed $(80.8 \%)$ (Fig. $4 C)$. The relative fraction of neurons from controls defined as burst-like multimodal (all bimodal) was $15.4 \%$, and one neuron was classified by regular firing $(3.9 \%)$ (Fig.
$4 C)$. Likewise, $80.0 \%$ of the EPN neurons from older $d t^{s z}$ hamsters were defined as burst-like skewed, and $20.0 \%$ were classified as burst-like multimodal (four neurons were defined by a bimodal and one neuron by a trimodal ISI distribution). There were no significant differences in the qualitative classifications of EPN neuronal discharge patterns between dystonic and nondystonic hamsters after spontaneous remission of stress-inducible attacks (Fig. 4). The $p$ values obtained by intergroup comparisons were as follows: burst-like skewed, $p=$ 1.00; burst-like multimodal, $p=0.727$; and regular, $p=1.00$.

However, comparable with the finding in younger animals, quantitative evaluation of the ISIH parameters revealed a significantly lower kurtosis in older mutant hamsters compared with age-matched controls $(5.35 \pm 0.61$ vs $11.63 \pm 1.29 ; p<0.0001)$ (Fig. 5D). This reduction was observed in the absence of significant differences in discharge rates between dystonic and nondystonic hamsters (Table 1). Accordingly, in older animals, the kurtosis was not correlated with the discharge rates of the EPN neurons (Table 1$)$. The mean ISI $(35.93 \pm 1.39$ vs $34.17 \pm 1.79$ msec; $p=0.239)$ (Fig. $5 A)$, the mode $(5.02 \pm 1.33$ vs $4.04 \pm 1.17$ msec; $p=0.524)$ (Fig. $5 B)$, and the asymmetry index $(0.13 \pm 0.03$ vs $0.12 \pm 0.03 ; p=0.873$ ) (Fig. $5 C$ ) did not differ significantly between older mutants and older controls. The mean ISI was significantly correlated with the discharge rates of the EPN neurons (Table 1).

\section{Evaluation of age-dependent changes}

When the discharge patterns of EPN neurons from $d t^{s z}$ hamsters at the most sensitive age of dystonia were compared with the discharge patterns from $d t^{s z}$ hamsters after spontaneous remission of stress-inducible attacks, a significant normalization was found. In young mutants, 11 of 30 neurons fired irregularly (Fig. $2 C)$, whereas this pattern has never been observed in older animals (Fig. $4 C$ ). This difference was significant $(p=0.0005)$. Accordingly, the relative number of neurons classified as burstlike skewed increased significantly in older $d t^{s z}$ hamsters $(p=$ 0.0009). There was no significant difference between young and older $d t^{s z}$ hamsters regarding the neurons defined as burst-like multimodal $(p>0.05)$. No significant age-dependent changes were evident in nondystonic control animals $(p>0.05$ for all defined cell types).

An ontogenetic comparison of the ISIH parameters of the EPN neurons (Figs. 3, 5) revealed a trend toward a decreased mean ISI in nondystonic hamsters $(p=0.099)$ and a significant decrease of the mean ISI in $d t^{s z}$ hamsters $(p<0.0001)$. Because in both animal groups the mean ISI is significantly (negatively) correlated with the discharge rate (Table 1), the finding of lowered mean ISIs can be attributed to the higher mean discharge rates found in older animals (Table 1).

Although not significantly different, the mean EPN discharge rate was found to be increased by $\sim 20 \%$ in older control hamsters (Table 1). The discharge rates of mutant hamsters, however, increased significantly in older animals by $\sim 230 \%$ (Table 1 ). In accordance, the decrease in the mean ISI was much stronger with increased age in $d t^{s z}$ hamsters than in controls (for exact values, refer to above paragraphs). The mode significantly decreased in both older dystonic and older nondystonic hamsters $(p=0.027$ in mutants and $p=0.016$ in controls). No significant age-dependent changes of the asymmetry index and the kurtosis were evident in nondystonic hamsters $(p>0.05)$. The $d t^{s z}$ hamsters, however, showed a significant reduction of the asymmetry index $(p=0.013)$ and 
1

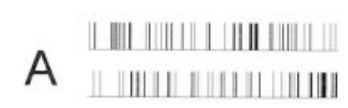

2

\section{|||||||| || |||||||||||||||||| ||||||||||| |||||||| ||||| ||| |||||}
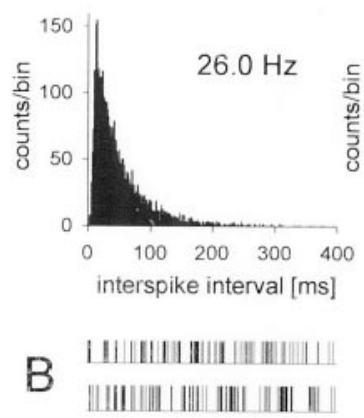

3
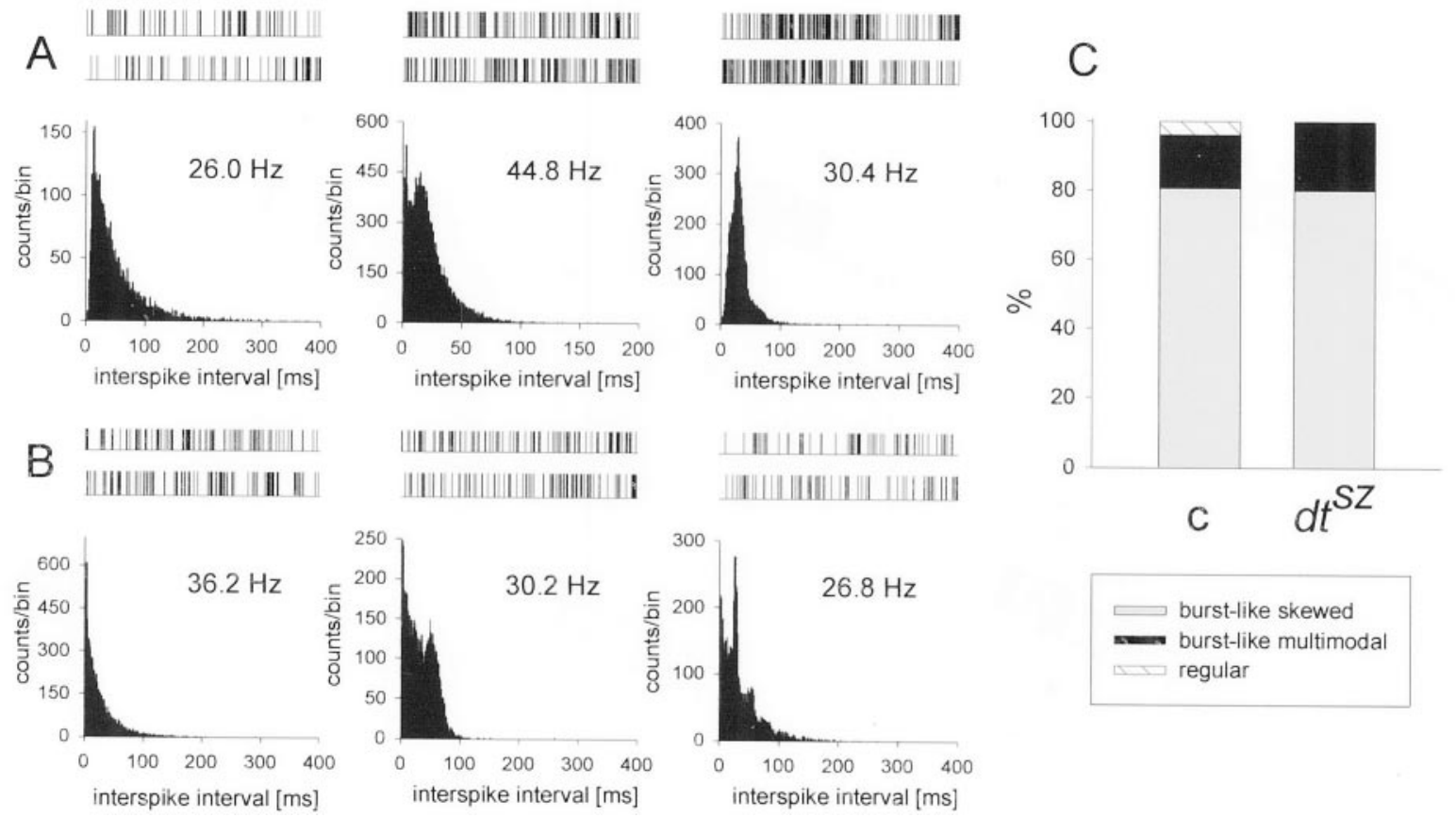

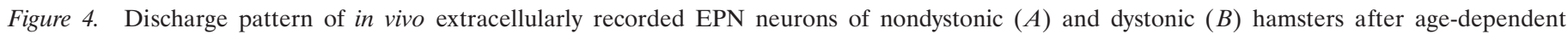

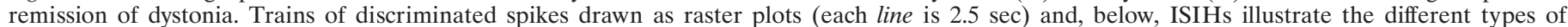

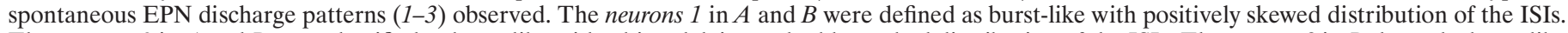

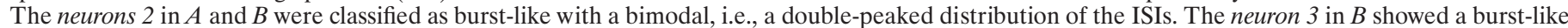

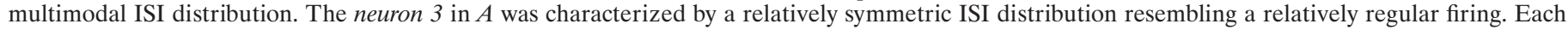

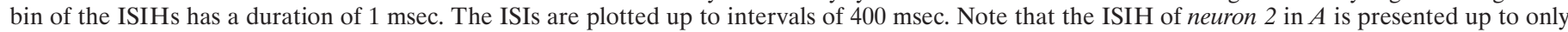

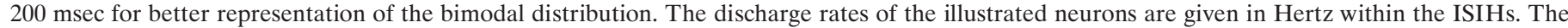

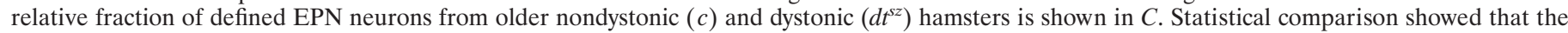

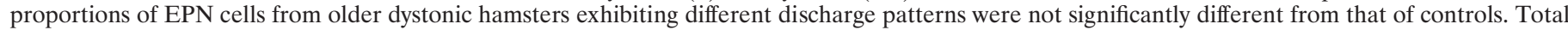

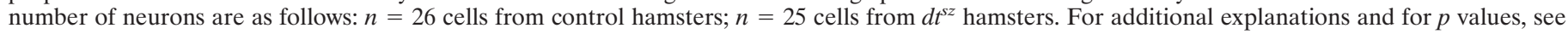
Results.

a significant increase of the kurtosis $(p=0.002)$ after spontaneous remission of stress-inducible dystonic attacks.

\section{Discharge pattern of $\mathrm{SNr}$ neurons at the most sensitive age of dystonia}

A total of 61 neurons recorded from the $\mathrm{SNr}$ of 46 hamsters could be used for analysis of spontaneous discharge patterns at the most sensitive age of dystonia, of which 40 neurons were from $31 d t^{s z}$ hamsters and 21 neurons were from 15 nondystonic control hamsters. An example of electrode location is shown in Figure $1 B$.

$\mathrm{SNr}$ neurons of nondystonic control hamsters showed four different spontaneous discharge patterns based on the ISIHs and visual inspection of the spike trains. These patterns ranged from burst-like skewed, burst-like multimodal, irregular, and burst firing (for examples, see Fig. 6A). Intermediate forms were common. Most SNr neurons of nondystonic control hamsters showed either a burst-like skewed pattern or irregular firing (42.9\% each) (Fig. 6C). A burst-like multimodal (bimodal) pattern was observed in $9.5 \%$ of the $\mathrm{SNr}$ neurons from controls. One of $21 \mathrm{SNr}$ neurons (Fig. 6A, neuron 4) was found to fire in bursts (4.8\%).

$\mathrm{SNr}$ neurons of $d t^{z z}$ hamsters showed discharge patterns ranging from burst-like skewed, burst-like multimodal, irregular, and regular firing (for examples, see Fig. $6 B$ ). Most neurons were defined as either burst-like skewed $(42.5 \%)$ or irregular firing $(37.5 \%)$ (Fig. 6C). One SNr neuron of $d t^{s z}$ hamsters was defined as burst-like multimodal (bimodal, 2.5\%). Different from the nondystonic control hamsters, some $\mathrm{SNr}$ neurons of $d t^{s z}$ hamsters were found to show a symmetric distribution of the ISIs (17.5\%) (Fig. 6B, neuron 4). The proportion of different $\mathrm{SNr}$ firing patterns in mutants did not indicate any significant differences from that of nondystonic controls (Fig. 6C). The $p$ values obtained by intergroup comparisons were as follows: burst-like skewed, $p=$ 1.00; burst-like multimodal, $p=0.270$; irregular, $p=0.785$; bursting, $p=0.344$; and regular, $p=0.084$.

Accordingly, no significant intergroup differences became evident after quantitative evaluation of the ISIH parameters mean ISI $(50.95 \pm 2.85 \mathrm{msec}$ in mutants vs $50.57 \pm 4.28 \mathrm{msec}$ in controls; $p=0.897)$ (Fig. $7 A)$, mode $(17.22 \pm 2.40 \mathrm{msec}$ vs $10.83 \pm 2.48 \mathrm{msec} ; p=0.060)$ (Fig. $7 B)$, asymmetry index $(0.34 \pm$ 0.04 vs $0.23 \pm 0.04 ; p=0.100$ ) (Fig. $7 C$ ), and kurtosis (10.73 \pm 3.54 vs $9.14 \pm 2.17 ; p=0.716$ ) (Fig. $7 D$ ). The mean ISI and the kurtosis were significantly correlated with the discharge rates of SNr neurons (Table 1).

\section{DISCUSSION}

Here we provide the first comprehensive ontogenetic investigation of the spontaneous discharge pattern of basal ganglia output neurons in a thoroughly defined animal model for idiopathic dystonia. When compared with nondystonic control animals, one main finding of the present study was a significant shift toward irregular and rhythmic burst-like firing of EPN neurons, i.e., one 

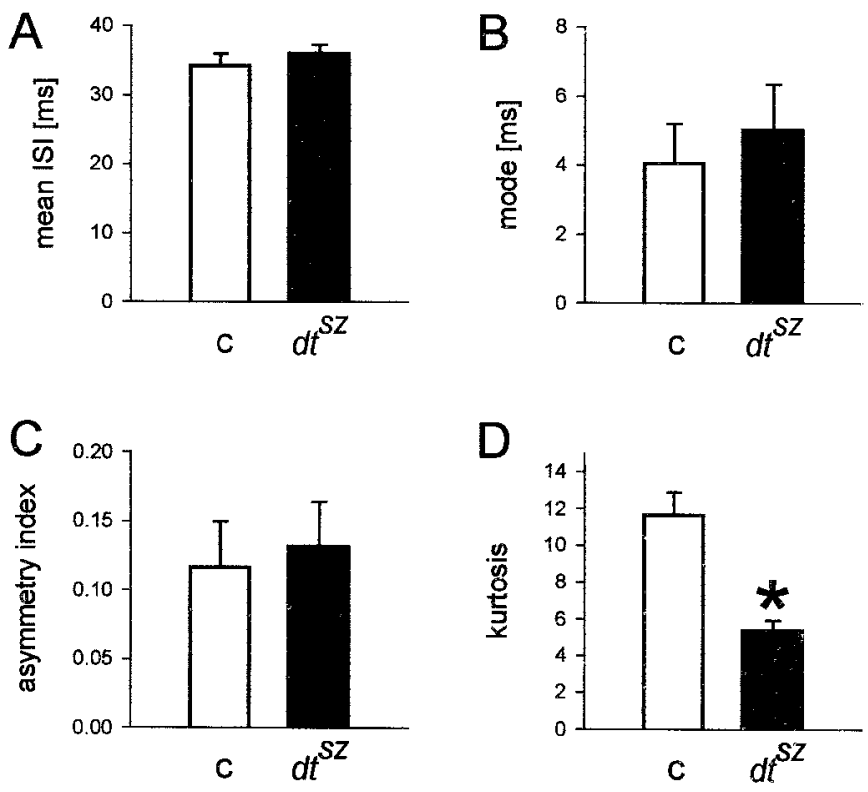

Figure 5. Quantitative evaluation of ISIH parameters of EPN neurons recorded extracellularly from nondystonic control hamsters $(c ; n=26$ neurons) and dystonic hamsters ( $d t^{s z} ; n=25$ neurons) after spontaneous remission of stress-inducible dystonic attacks. Error bars represent mean + SE. There were no significant intergroup differences in the mean ISI $(A)$, the mode $(B)$, and the asymmetry index $(C)$. The kurtosis $(D)$ was significantly lower in $d t^{s z}$ hamsters compared with controls $(* p<0.01)$. For additional explanations and for exact $p$ values, see Results.

of the two major basal ganglia output structures, in $d t^{s z}$ hamsters at the age at which the most marked expression of dystonia is typically observed. This increased fraction of irregularly firing EPN neurons is not secondary to the motor disturbances, because this change in discharge pattern was found to occur in the absence of motor attacks. Although we cannot exclude that the observed discharge patterns might be state dependent, i.e., influenced by the used anesthesia, significant differences between dystonic and nondystonic animals nevertheless were clearly demonstrable. Interestingly, an increased irregularity of spontaneous firing was also indicated by intrasurgical recordings of GPi neurons in patients with generalized dystonia when compared with patients suffering from idiopathic Parkinson's disease (Vitek et al., 1999). Additionally, a change in the pattern of GPi neurons was reported for Parkinson's disease patients developing drug-induced dyskinesias (Merello et al., 1999).

In line with the current concept that dystonia in humans is related to a lowered mean discharge rate of pallidothalamic neurons (Wichmann and DeLong, 1996; Vitek and Giroux, 2000), we provided recently evidence for a dramatic reduction of the mean spontaneous EPN discharge rate in $d t^{s z}$ hamsters at the most sensitive age of dystonia when compared with nondystonic controls (Gernert et al., 2000). The lowered EPN activity in mutants was postulated to result from a functional inhibition by overactive striatal GABAergic projection neurons via the socalled direct pathway, i.e., the monosynaptic inhibitory pathway from the striatum to the basal ganglia output structures, and was attributed to a significant bilateral reduction of the number and density of parvalbumin-immunoreactive GABAergic interneurons within the striatum of $d t^{s z}$ hamsters (Gernert et al., 1999a, 2000). A decreased mean discharge rate of GPi neurons was also indicated by intrasurgical recordings in dystonic patients (Vitek et al., 1999; Hashimoto, 2000) and by positron emission tomography studies, the latter one demonstrating increased metabolism in the lentiform nucleus and decreased metabolismus in the thalamus (Eidelberg, 1998).

However, a decreased mean discharge rate in the EPN cannot, by itself, account for the development of idiopathic dystonias, as can be concluded from the ameliorating effects of pallidotomy (Lozano et al., 1997; Bhatia et al., 1998; Ondo et al., 1998; Vitek et al., 1998). Additional changes in the discharge pattern of EPN neurons may lead to relevant changes in the activity of thalamic target neurons. Previous quantitative electroencephalic depth electrode recordings indicated an altered neuronal synchronization in the striatum and globus pallidus (GP) (external GP in primates) of mutant hamsters (Gernert et al., 1998). Using singleunit recordings, we now showed an altered discharge pattern of EPN neurons in $d t^{s z}$ hamsters. The temporal coding of neural signals, although not fully understood, has been suggested to provide a more important representation of information transmission in neural systems than the mean firing rate (Ferster and Spruston, 1995). It is conceivable that removing the disturbed firing pattern of basal ganglia output neurons, which is hypothesized to interfere with the pattern and degree of synchronization of thalamocortical signal transmission by disrupting the normal temporal pattern and thereby resulting in disordered motor control (Wichmann and DeLong, 1996; Vitek and Giroux, 2000), outweighs the additional reduction of basal ganglia output obtained by pallidotomy.

Furthermore, pallidotomy in dystonic patients is typically restricted to the sensomotor portion of the GPi (Lozano et al., 1997; Bhatia et al., 1998; Ondo et al., 1998; Vitek et al., 1998). Despite removal of an altered discharge pattern, a complete pallidotomy would be expected to worsen dystonia because of the resulting complete loss of pallidothalamic activity. Indeed, complete lesions of the EPN in $d t^{s z}$ hamsters resulted in increased severity of dystonia (Richter et al., 2001).

We found the altered firing pattern and discharge rate of EPN neurons to be significantly correlated in $d t^{s z}$ hamsters. An increased inhibitory input from the striatum via the direct pathway (Gernert et al., 1999a) is therefore likely to account not only for the changes in discharge rate (Gernert et al., 2000) but also for the altered firing pattern observed in the present study. This is supported by in vitro electrophysiological investigations showing that the discharge pattern of EPN neurons depends on their level of membrane polarization (Nakanishi et al., 1990; Nambu and Llinás, 1994).

As mentioned in the introductory remarks, the age dependence of stress-inducible paroxysmal dystonia in $d t^{s z}$ hamsters enables ontogenetic studies of the importance of changes in the pathogenesis of dystonia. Changes detected at the age of maximum severity should be reduced or disappeared in older animals, which had lost their susceptibility to stress-inducible attacks. Previous ontogenetic studies revealed that several changes, including a deficit of striatal GABA levels, the hyperactivity of striatal projection neurons, and the lowered activity of EPN neurons, found in mutant hamsters at the most sensitive age of dystonia completely disappeared in older animals that had lost their susceptibility to stress-inducible dystonia (Löscher and Hörstermann, 1992; Pratt et al., 1995; Gernert et al., 1999a, 2000; Bennay et al., 2001). Accordingly, the present study revealed an almost complete normalization of the changes in discharge pattern after spontaneous remission of dystonia in $d t^{s z}$ hamsters, supporting the functional relevance 
1
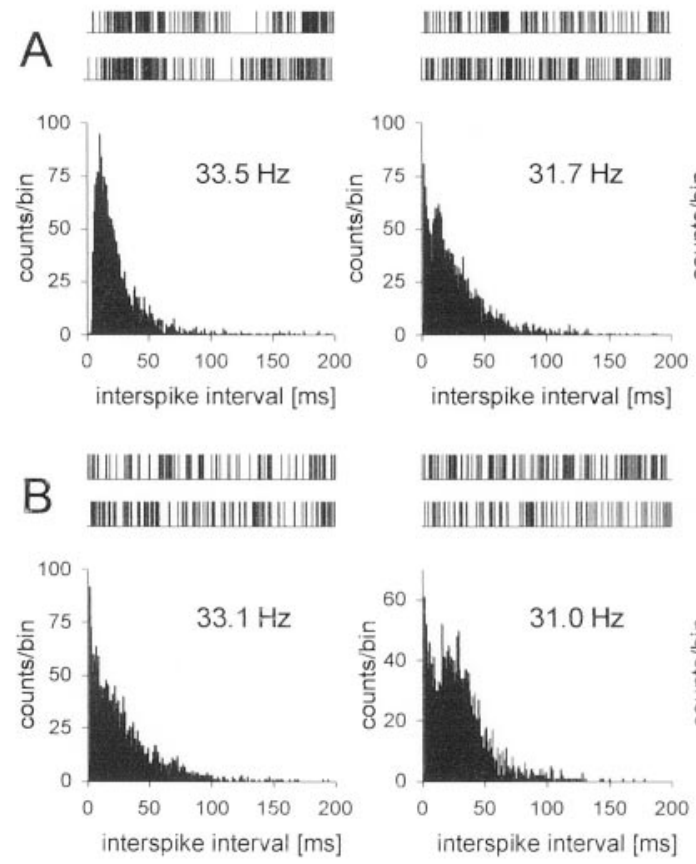

2

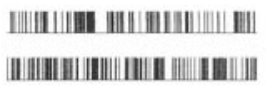

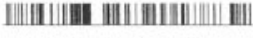

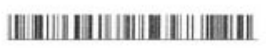

Ш|||||||||| ||||||||||||||||||

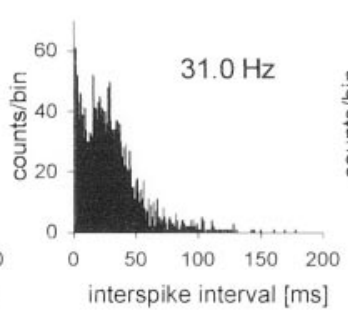

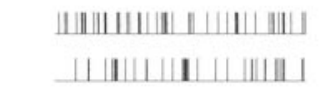

3
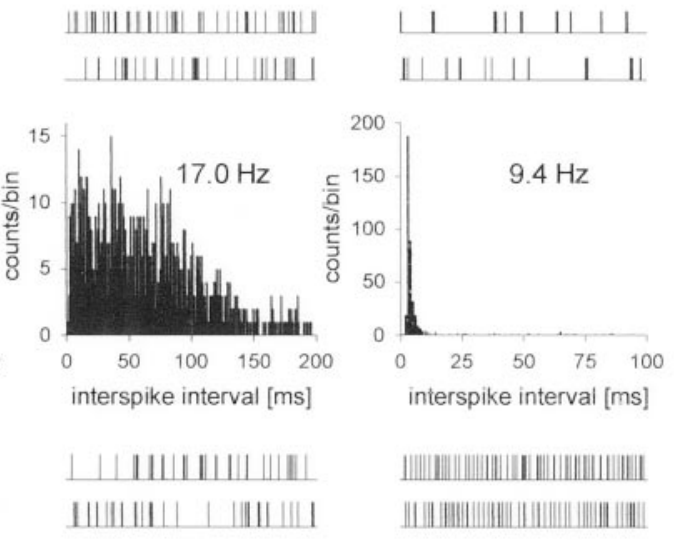

4
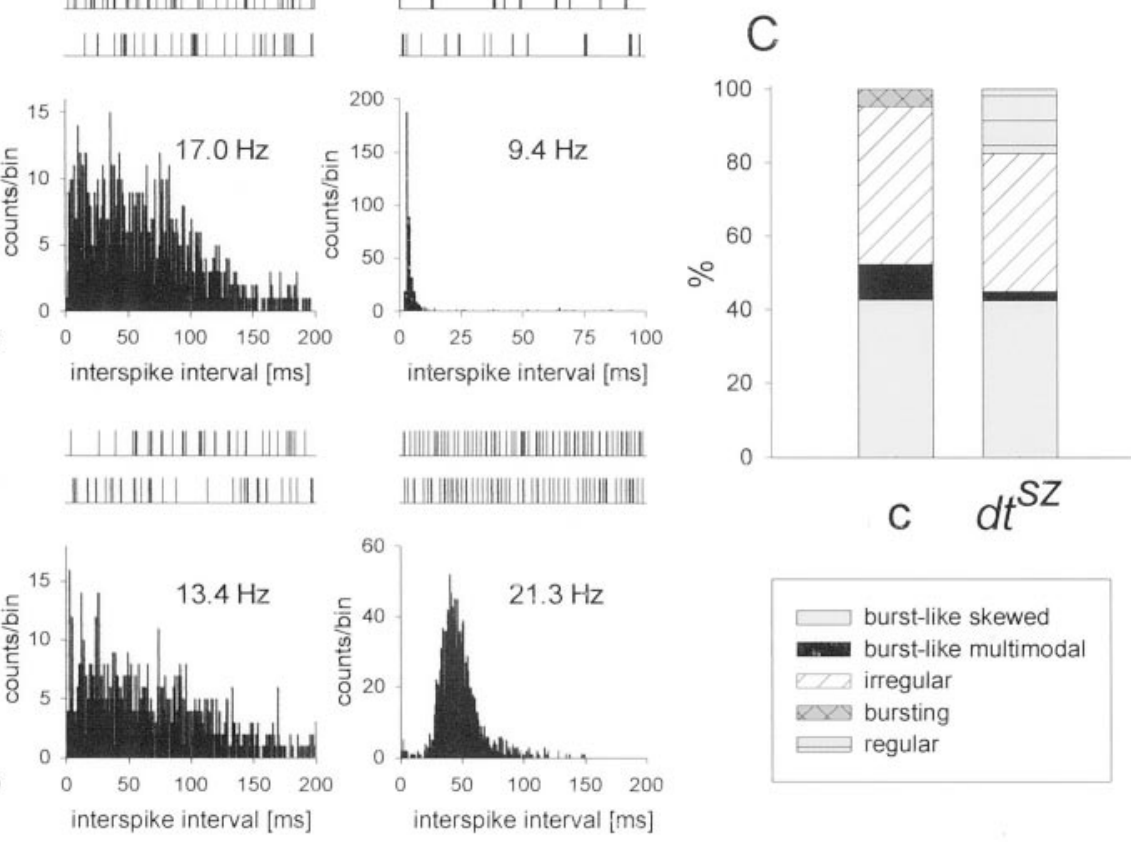

Figure 6. Discharge pattern of in vivo extracellularly recorded $\mathrm{SNr}$ neurons of nondystonic $(A)$ and dystonic $(B)$ hamsters at the most sensitive age of dystonia. Trains of discriminated spikes drawn as raster plots (each line is $2.5 \mathrm{sec}$ ) and, below, ISIHs illustrate the different types of spontaneous SNr discharge patterns (1-4) observed. The neurons 1 in $A$ and $B$ were defined as burst-like with positively skewed distribution of the ISIs. The neurons 2 in $A$ and $B$ were classified as burst-like with a bimodal, i.e., a double-peaked distribution of the ISIs. The neurons 3 in $A$ and $B$ were characterized by a random ISI distribution resembling irregular firing. The neuron 4 in $A$ showed a bursting pattern and a narrow-ranged, positively skewed, ISI distribution. The neuron 4 in $B$ showed regular firing characterized by a symmetric ISI distribution. Each bin of the ISIHs has a duration of $1 \mathrm{msec}$. The ISIs are plotted up to intervals of $200 \mathrm{msec}$. Note that the ISIH of neuron 4 in $A$ is presented up to only $100 \mathrm{msec}$ for better representation of the extremely narrow-ranged ISI distribution. The discharge rates of the illustrated neurons are given in Hertz within the ISIHs. The relative fraction of defined SNr neurons from nondystonic $(c)$ and dystonic $\left(d t^{s z}\right)$ hamsters is shown in $C$. Statistical comparison showed that the proportions of SNr cells from dystonic hamsters exhibiting different discharge patterns were not significantly different from that of controls. Total number of neurons are as follows: $n=21$ cells from control hamsters; $n=40$ cells from $d t^{s z}$ hamsters. For additional explanations and for $p$ values, see Results.

of an altered EPN discharge pattern for the expression of paroxysmal dystonia. In these older animals, no significant difference of defined firing patterns between dystonic and nondystonic hamsters were detected. However, the kurtosis was still significantly reduced, indicating a permanently higher overall irregularity in firing of EPN neurons in mutants. Although older $d t^{s z}$ hamsters are insensitive to induction of dystonia by stress, previous studies suggest that they still carry a latent susceptibility for drug-induced dystonia (Richter et al., 1994, 1997) and for induction of dystonia by hormonal modulation in females (Khalifa and Iturrian, 1993). These findings might be explained by moderate long-term changes in information processing on the level of the basal ganglia in $d t^{s z}$ hamsters.

In contrast to the findings from Vitek et al. (1999), no changes in spontaneous discharge rates and only slight changes in firing pattern of GP neurons were found in $d t^{s z}$ hamsters (Gernert et al., 1999b). Recent electrophysiological investigations of the $\mathrm{SNr}$, i.e., the second major output structure of the basal ganglia, revealed a higher susceptibility of $\mathrm{SNr}$ output neurons for drugs that disturb GABAergic function in mutants at the age of maximum severity of dystonia (Gernert et al., 1999c; Fedrowitz et al., 2002). However, no changes of the spontaneous discharge rates became evident in the SNr (Gernert et al., 1999c; Fedrowitz et al., 2002). Thus, at least in the absence of dystonic attacks, the indirect pathway of the basal ganglia circuit via the GP and subthalamic nucleus to the output nuclei EPN and $\mathrm{SNr}$ might play a less relevant role in the pathogenesis of dystonia. In line with this idea, the present data did not show any significant differences in spontaneous discharge patterns of $\mathrm{SNr}$ neurons between dystonic and nondystonic animals in the absence of dystonic attacks. In fact, GABAergic SNr projection neurons, recorded intracellularly, have been proposed to produce a frequency coded output (Richards et al., 1997).

In conclusion, the present findings of an age-dependent shift toward highly irregular and altered burst-like firing of EPN neurons in $d t^{z z}$ hamsters provide evidence that dystonias develop as the result of a combination of excessive reductions (Gernert et al., 2000; Bennay et al., 2001) together with a changed discharge pattern of EPN neurons. In view of the present findings of an abnormal firing pattern, the dystonic hamster model seems to be suited to investigate in future studies the mechanisms of deep brain stimulation of the EPN, a treatment known to ameliorate dystonia in patients (Krack and Vercueil, 2001). It is postulated that a heterogeneous pathogenesis of different types of idiopathic dystonia and other dyskinesias may result in common neural disturbances (Wichmann and DeLong, 1996). Apart from idiopathic dystonias, the present evidence for an altered EPN firing pattern may, therefore, also be important for other idiopathic or symptomatic dyskinesias, for which a reduced basal ganglia out- 

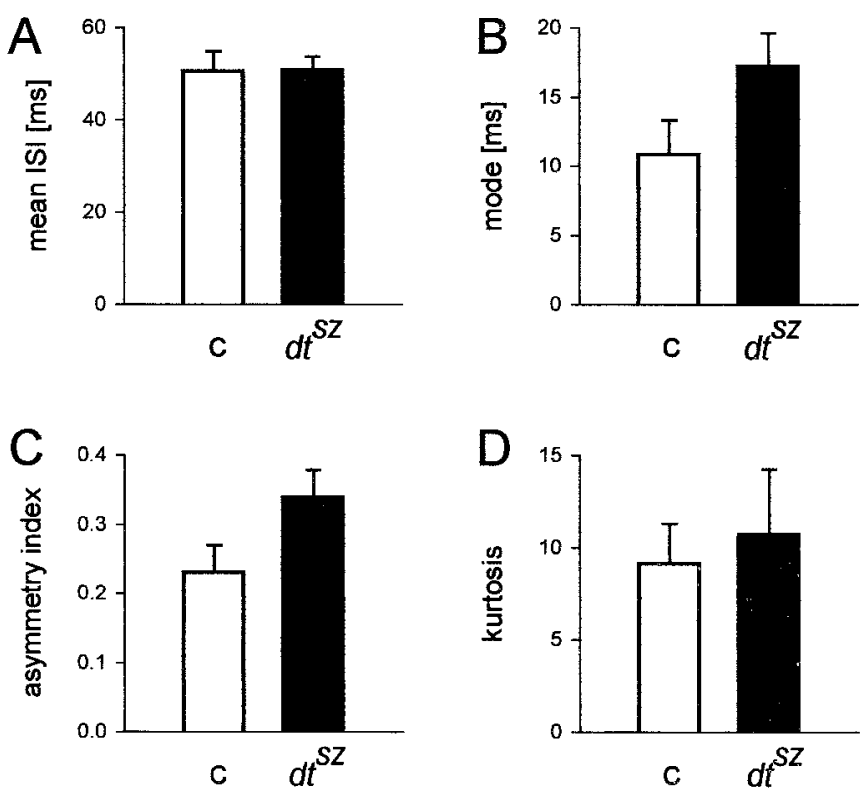

Figure 7. Quantitative evaluation of ISIH parameters of $\mathrm{SNr}$ neurons recorded extracellularly from nondystonic control hamsters $(c ; n=21$ neurons) and dystonic hamsters ( $d t^{s z} ; n=40$ neurons) at the most sensitive age of dystonia. Error bars represent mean $+\mathrm{SE}$. There were no significant intergroup differences in the mean ISI $(A)$, the mode $(B)$, the asymmetry index $(C)$, and the kurtosis $(D)$. For additional explanations and for $p$ values, see Results.

put activity is hypothesized (Mitchell et al., 1990; Wichmann and DeLong, 1996; Suarez et al., 1997; Berardelli et al., 1998; Crossman and Brotchie, 1998; Hallett, 1998; Merello et al., 1999; Filion, 2000; Vitek and Giroux, 2000).

\section{REFERENCES}

Bennay M, Gernert M, Richter A (2001) Spontaneous remission of paroxysmal dystonia coincides with normalization of entopeduncular activity in $d t^{\text {sz }}$ mutants. J Neurosci 21:RC153(1-4).

Berardelli A, Rothwell JC, Hallett M, Thompson PD, Manfredi M, Marsden CD (1998) The pathophysiology of primary dystonia. Brain 121:1195-1212.

Bhatia KP, Marsden CD, Thomas DG (1998) Posteroventral pallidotomy can ameliorate attacks of paroxysmal dystonia induced by exercise. J Neurol Neurosurg Psychiatry 65:604-605.

Ceballos-Baumann AO, Passingham RE, Marsden CD, Brooks DJ (1995) Motor reorganization in acquired hemidystonia. Ann Neurol 37:746-757.

Crossman AR, Brotchie JM (1998) Pathophysiology of dystonia. In: Advances in neurology, Dystonia 3, Vol 78 (Fahn S, Marsden CD, DeLong MR, eds), pp 19-25. New York: Lippincott-Raven.

Demirkiran M, Jankovic J (1995) Paroxysmal dyskinesias: clinical features and classification. Ann Neurol 38:571-579.

Eidelberg D (1998) Abnormal brain network in DYT1 dystonia. In: Advances in neurology, Dystonia 3, Vol 78 (Fahn S, Marsden CD, DeLong MR, eds), pp 127-133. New York: Lippincott-Raven.

Fahn S, Bressman SB, Marsden CD (1998) Classification of dystonia. In: Advances in neurology, Dystonia 3, Vol 78 (Fahn S, Marsden CD, DeLong MR, eds), pp 1-10. New York: Lippincott-Raven.

Fedrowitz M, Hamann M, Rehders JH, Richter A, Gernert M (2002) Effects of locally administered pentylenetetrazole on nigral single unit activity and severity of dystonia in a genetic model of paroxysmal dystonia. J Neurosci Res 68:595-603.

Ferster D, Spruston N (1995) Cracking the neuronal code. Science 270:756-757.

Filion M (2000) Physiologic basis of dyskinesia. Ann Neurol 47:S35-S41. Gernert M, Richter A, Rundfeldt C, Löscher W (1998) Quantitative EEG analysis of depth electrode recordings from several brain regions of mutant hamsters with paroxysmal dystonia discloses frequency changes in the basal ganglia. Mov Disord 13:509-521.

Gernert M, Richter A, Löscher W (1999a) Alterations in spontaneous single unit activity of striatal subdivisions during ontogenesis in mutant dystonic hamsters. Brain Res 821:277-285.

Gernert M, Richter A, Löscher W (1999b) In vivo extracellular electro- physiology of pallidal neurons in dystonic and nondystonic hamsters. J Neurosci Res 57:894-905.

Gernert M, Richter A, Löscher W (1999c) Subconvulsive dose of pentylenetetrazole increases the firing rate of substantia nigra pars reticulata neurons in dystonic but not in nondystonic hamsters. Synapse 33:259-267.

Gernert M, Hamann M, Bennay M, Löscher W, Richter A (2000) Deficit of striatal parvalbumin-reactive GABAergic interneurons and decreased basal ganglia output in a genetic rodent model of idiopathic paroxysmal dystonia. J Neurosci 20:7052-7058.

Guehl D, Burbaud P, Boraud T, Bioulac B (2000) Bicuculline injections into the rostral and caudal motor thalamus of the monkey induce different types of dystonia. Eur J Neurosci 12:1033-1037.

Hallett M (1998) The neurophysiology of dystonia. Arch Neurol 55:601-603.

Hashimoto T (2000) Neuronal activity in the globus pallidus in primary dystonia and off-period dystonia. J Neurol 247 [Suppl 5]:V49-V52.

Hassani O-K, Mouroux M, Féger J (1996) Increased subthalamic neuronal activity after nigral dopaminergic lesion independent of disinhibition via the globus pallidus. Neuroscience 72:105-115.

Khalifa AE, Iturrian WB (1993) Triphasic relapse in dystonic hamster during pregnancy as a rigorous neurochemical model for movement disorder. Soc Neurosci Abstr 19:1626.

Krack P, Vercueil L (2001) Review of the functional surgical treatment of dystonia. Eur J Neurol 8:389-399.

Kramer PL, Bressman SB, Fahn S, Ozelius L, Breakefield XO (1995) The genetics of dystonia. In: Handbook of dystonia (Tsui JKC, Calne DB, eds), pp 43-58. New York: Dekker.

Löscher W, Hörstermann D (1992) Abnormalities in amino acid neurotransmitters in discrete brain regions of genetically dystonic hamsters. J Neurochem 59:689-694.

Löscher W, Fisher Jr JE, Schmidt D, Fredow G, Hönack D, Iturrian W B (1989) The sz mutant hamster: a genetic model of epilepsy or of paroxysmal dystonia? Mov Disord 4:219-232.

Löscher W, Rohlfs A, Rundfeldt C (1995) Reduction in firing rate of substantia nigra pars reticulata neurons by valproate: influence of different types of anesthesia in rats. Brain Res 702:133-144.

Lozano AM, Kumar R, Gross RE, Giladi N, Hutchison WD, Dostrovsky JO, Lang AE (1997) Globus pallidus internus pallidotomy for generalized dystonia. Mov Disord 12:865-870.

Merello M, Balej J, Delfino M, Cammarota A, Betti O, Leiguarda R (1999) Apomorphine induces changes in GPi spontaneous outflow in patients with Parkinson's disease. Mov Disord 14:45-49.

Mitchell IJ, Luquin R, Boyce CE, Robertson RG, Sambrook MA, Crossman AR (1990) Neural mechanisms of dystonia: evidence from a 2-deoxyglucose uptake study in a primate model of dopamine agonistinduced dystonia. Mov Disord 5:49-54.

Nakanishi H, Kita H, Kitai ST (1990) Intracellular study of rat entopeduncular nucleus neurons in an in vitro slice preparation: electrical membrane properties. Brain Res 527:81-88.

Nambu A, Llinás R (1994) Electrophysiology of globus pallidus neurons in vitro. J Neurophysiol 72:1127-1139.

Ni Z, Bouali-Benazzouz R, Gao D, Benabid A-L, Benazzouz A (2000) Changes in the firing pattern of globus pallidus neurons after the degeneration of nigrostriatal pathway are mediated by the subthalamic nucleus in the rat. Eur J Neurosci 12:4338-4344.

Ondo WG, Desaloms JM, Jankovic J, Grossman RG (1998) Pallidotomy for generalized dystonia. Mov Disord 13:693-698.

Paxinos G, Watson C (1998) The rat brain in stereotaxic coordinates. Sydney: Academic.

Playford ED, Passingham RE, Marsden CD, Brooks DJ (1998) Increased activation of frontal areas during arm movement in idiopathic torsion dystonia. Mov Disord 13:309-318.

Pratt GD, Richter A, Möhler H, Löscher W (1995) Regionally selective and age-dependent alterations in benzodiazepine receptor binding in the genetically dystonic hamster. J Neurochem 64:2153-2158.

Richards CD, Shiroyama T, Kitai ST (1997) Electrophysiological and immunocytochemical characterization of GABA and dopamine neurons in the substantia nigra of the rat. Neuroscience 80:545-557.

Richter A, Löscher W (1993) Alterations in pharmacological sensitivity of GABAergic but not dopaminergic and glutamatergic systems during ontogenesis in dystonic mutant hamsters. Eur J Pharmacol 231:111-119.

Richter A, Löscher W (1998) Pathology of idiopathic dystonia: findings from genetic animal models. Prog Neurobiol 54:633-677.

Richter A, Löschmann P-A, Löscher W (1994) The novel antiepileptic drug lamotrigine exerts prodystonic effects in a mutant hamster model of generalized dystonia. Eur J Pharmacol 264:345-351.

Richter A, Gernert M, Löscher W (1997) Prodystonic effects of riluzole in an animal model of idiopathic dystonia related to decreased total power in the red nucleus? Eur J Pharmacol 332:133-142.

Richter A, Hamann M, Bennay M, Löscher W, Gernert M (2001) Relevance of decreased entopeduncular activity in paroxysmal dystonia 
supported by neurolesions, microinjections and ontogenetic single unit recordings in a genetic animal model. Soc Neurosci Abstr 27:514.13.

Rohrbacher J, Ichinohe N, Kitai ST (2000) Electrophysiological characteristics of substantia nigra neurons in organotypic cultures: spontaneous and evoked activities. Neuroscience 97:703-714.

Simons DJ, Land PW (1987) A reliable technique for marking the location of extracellular recording sites using glass micropipettes. Neurosci Lett 81:100-104.

Suarez JI, Metman LV, Reich SG, Dougherty PM, Hallett M, Lenz FA (1997) Pallidotomy for hemiballismus: efficacy and characteristics of neuronal activity. Ann Neurol 42:807-811.

Vitek JL, Giroux M (2000) Physiology of hypokinetic and hyperkinetic movement disorders: model for dyskinesia. Ann Neurol 47:S131-S140.

Vitek JL, Zhang J, Evatt M, Mewes K, DeLong MR, Hashimoto T, Triche S, Bakay RA (1998) GPi pallidotomy for dystonia: clinical outcome and neuronal activity. In: Advances in neurology, Dystonia 3, Vol 78 (Fahn S, Marsden CD, DeLong MR, eds), pp 211-219. New York: Lippincott-Raven.

Vitek JL, Chockkan V, Zhang JY, Kaneoke Y, Evatt M, DeLong MR, Triche S, Mewes K, Hashimoto T, Bakay RA (1999) Neuronal activity in the basal ganglia in patients with generalized dystonia and hemiballismus. Ann Neurol 46:22-35.

Wichmann T, DeLong MR (1996) Functional and pathophysiological models of the basal ganglia. Curr Opin Neurobiol 6:751-758. 